\title{
Nocete, F. y Nocete, F.J. (2015): Mil años de historia escrita en cobre y oro/ A thousand years of history written in copper and gold. Huelva, Fundación Atlantic Copper. 55 págs. y numerosas fotografías en color. (44 cm x $24,5 \mathrm{~cm}$.) ISBN: 978-84-606-9996-5
}

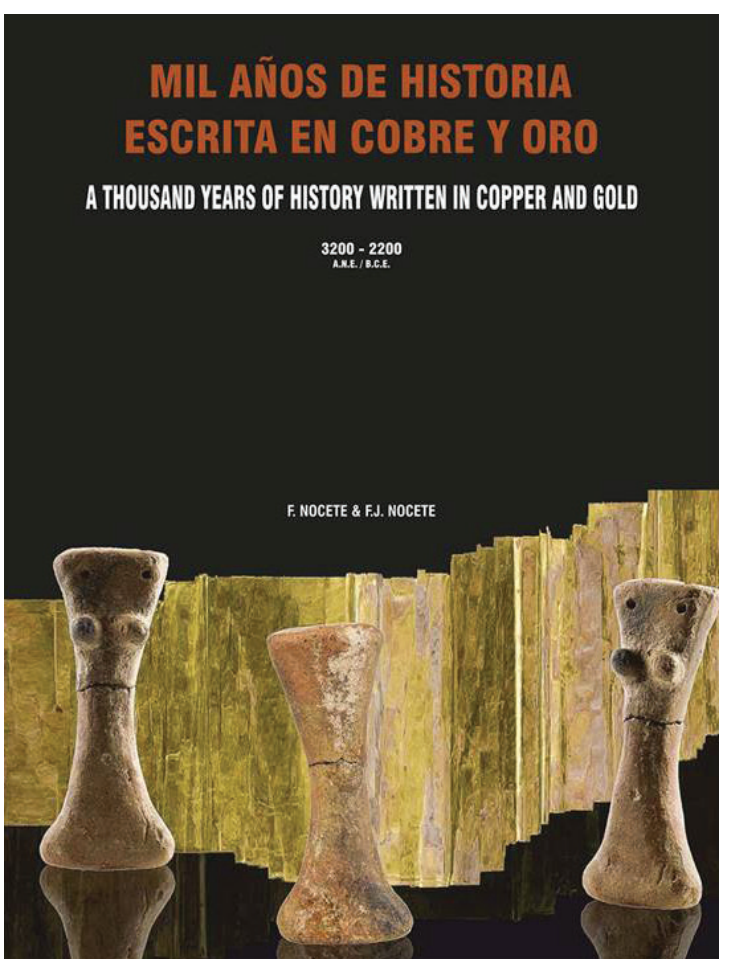

Escribir arqueología para los no expertos, que interese además a los propios especialistas, no es fácil. Hacerlo de forma que el pasado estudiado se extienda al presente para descubrir como el pasado influye y ayuda a explicarlo y hacerlo de forma comprometida socialmente resulta más difícil todavía. Y presentar ese pasado/ presente para visualizarlo poderosamente con una buena coordinación texto/imagen es extraordinariamente difícil. Pues bien, este libro hace todo eso y lo hace muy bien. A pesar de que los profesionales de la arqueología valoran sobre todo las monografías que aportan nuevos conocimientos, menos los libros de divulgación aunque estén bien escritos y presentados, escasamente los manuales pensados para la enseñanza y bastante poco cualquier obra que ofrezca una mezcla sugestiva de esos tres géneros, este libro debe interesar a todo tipo de lectores.

El Prof. Francisco Nocete (Universidad de Huelva) cuenta con una excelente trayectoria investigadora, muy seria con sus planteamientos teóricos y metodológicos, con un gran trabajo de campo en yacimientos como Cabezo Juré, La Junta de los Ríos y Valencina de la Concepción, con publicaciones destacadas y cuidando siempre una proyección internacional que a estas alturas es muy amplia y bien reconocida. Los orígenes de la primera metalurgia en el mediodía peninsular -especialmente el Suroeste-, la aparición y organización de las primeras sociedades de clase y la emergencia de las estructuras estatales desde una perspectiva materialista histórica han constituido el centro de sus investigaciones. Y buena parte de esa dilatada experiencia la ha volcado en este deslumbrante libro - con la valiosa ayuda de la mirada de su hijo-que demuestra como se puede divulgar, sin perder rigor, interesar y despertar la curiosidad por el pasado y mover a la reflexión de la historia larga, la historia que desde un pasado lejano descubre las implicaciones del primer trabajo del metal en la forma en que esos metales se siguen produciendo y usando en el mundo actual. De alguna forma, el pasado está siempre en el presente, y trazas, indicios, huellas, persistencias y rastros asoman hoy por muchos sitios, aunque sea mínimamente, para aquellos investigadores que saben mirar profundamente lo que queda del pasado.

La idea del libro es ofrecer un historia de 5000 años de la metalurgia en el Suroeste peninsular, especialmente Huelva y áreas limítrofes, con un énfasis en la etapa de la primera metalurgia entre 3200 y 2200 a.n.e. pero buscando, como señalaba más arriba implicaciones hasta nuestros días de esa historia escrita en cobre y oro. El libro es breve y está orientado a la divulgación rigurosa de dos décadas de investigación con textos cortos, bilingües (castellano-inglés), un aparato gráfico extraordinario, potente, didáctico y aún artístico, y una cuidada maquetación en páginas de fondo negro, de la que emergen las fantásticas fotografías a todo color con los textos en caracteres blancos y naranjas que realzan la estética de cada página. El esfuerzo editorial ha sido importante y los resultados lo justifican plenamente. 
La obra consta de 12 grandes apartados que se articulan en torno a: a) los contextos geográfico y cronológico, b) la cadena operativa del cobre: abastecimiento de materia prima, procesado del mineral, pirotecnología, refinado y moldeado y la manufactura final de productos, y c) su significación tecnológica, económica, social y política. Un apartado sobre el oro cierra el cuerpo del libro. En cada apartado se ha seguido un mismo esquema tripartito: primero, presentación de los datos básicos y estado de la cuestión; segundo, la contestación a la pregunta "¿Cómo se ha llegado a esas conclusiones?: ciencia" (rematados con unas pocas referencias bibliográficas bien seleccionadas) $\mathrm{y}$, finalmente, la relación de cada tema con la situación actual bajo el epígrafe "Hoy". Lo que constituye un potente recordatorio de cómo en arqueología aunque los datos espectaculares, curiosos o interesantes suscitan interés en visitantes/lectores, el mismo interés suscita el relato de cómo se han descubierto los datos. Lo que sabemos y como lo sabemos, algo que no siempre recordamos al escribir divulgación y este libro aborda de forma ejemplar.

Los textos están muy bien pensados cumpliendoperfectamentelas recomendaciones académicas para divulgar (Connah 2010: 15455)-, con un esfuerzo notable para decir mucho con gran brevedad (entre 40 y poco más de 150 palabras). La explicación científica de cómo se ha llegado a cada conclusión me recuerda mucho la presentación del nuevo Hall of Human Origins en el Smithsonian's National Museum of Natural History de Washington, en el que cada gran afirmación de la exposición se acompaña de un círculo destacado con letras de gran formato que responde a la pregunta “Cómo sabemos esto?", en textos muy cortos, de 50-60 palabras, pero muy claros y directos. Observé que la mayoría gente los leía, en lo que interpreté como el límite superior de texto legible en una cartelería museográfica. Este libro hace casi lo mismo y no queda muy lejos de la increíble experiencia del Museo Thyssen de mostrar cuadros con tuits, sin llegar ni siquiera a los famosos 140 caracteres, que los complementan admirablemente (Solana 2013).

Pensar el tiempo de aquella primera metalurgia y como escribimos narrativas sobre el pasado podría beneficiarse de lo que el crítico británico-estadounidense J. Wood (2016) ha denominado la "vividad", la vida en una narrativa - de alguna forma una ficciónque no deja de ser una vida del pasado traída a una vida distinta por medio de la interpretación arqueológica. Y no sólo eso sino que también es distinta en como se expresa formalmente. Pero esto sería motivo de otra reflexión sobre las formas de escribir arqueología, especialmente en divulgación donde los registros pueden ser más ricos y diversos (Connah 2010, Ruiz Zapatero 2014: 24).

Pero la gran originalidad y valor del libro reside en que los textos breves, precisos $\mathrm{y}$ exactos se han redactado pensando en las imágenes y en como se complementan las extraordinarias fotografías de sitios y yacimientos arqueológicos con las instalaciones metalúrgicas modernas de cobre. Palabras y fotografías configuran un universo en el que las palabras alumbran imágenes sentipensantes, en término pirateado al escritor Manuel Rivas, y las fotografías generan acciones y procesos de una larga historia que une pasado y presente. Los contrastes son fantásticos. Los objetos calcolíticos -desde escorias y molinos y bolas para triturar mineral a toberas, crisoles, armas y herramientas- se confrontan con metalografías, fotografías etnográficas, circuitos de ordenador o aviones, en la medida en que mucha tecnología moderna de elementos que incorporan componentes eléctricos necesita cobre para su funcionamiento. Hasta el punto que algún estudio ha llegado a calificar el cobre como el metal con el que funciona el mundo actual (Carter 2014). Y es que en el Suroeste peninsular el trabajo pionero del cobre proporcionó medios y conocimientos para producir útiles y tecnología lo suficientemente poderosas como para moldear un nuevo mundo con el protagonismo activo de las sociedades de finales del IV milenio y del III milenio a. C. La metalurgia del cobre fue la primera gran industria de la Europa occidental y con ella y con otras transformaciones sociales y políticas aparecerán las primeras estructuras estatales. No deja de resultar absolutamente sorprendente e indicativo de la eficiencia de la antigua metalurgia que se puedan encontrar algunas continuidades asombrosas, por ejemplo, que el grosor de las toberas calcolíticas de $5 \mathrm{~cm}$ sea 
hoy día exactamente el mismo de las utilizadas en los convertidores Peirce Smith (págs. 2527).

Acaso el único reparo que se me ocurre a este libro sea que igual que se han buscado las implicaciones de la antigua metalurgia en el mundo actual se podría haber incluido un apartado final sobre la aparición de la metalurgia del cobre a nivel mundial. Para, ganando una perspectiva global, detallar los focos y cronologías de lo que parece fue un proceso de invención única en el Viejo Mundo con múltiples mecanismos de expansión de las tecnologías metalúrgicas por grupos de especialistas (Roberts et al. 2009).

Si leer es siempre un riesgo (Berardinelli 2016), leer como recensionista solo es posible asumiendo el riesgo de ser también un simple lector, un "lector sin defensas, sin pinzas, tijeras ni bisturí, un lector receptivo que acepte los riesgos de la lectura, que suspenda la incredulidad y crea, al menos mientras lee, en aquello que lee" como dice Berardinelli (2016: 32); y yo añado, también en lo que ve en las imágenes con los ojos de la cara y del cerebro.
Solo así lectura y conocimiento se convierten en algo más, pero el mérito está en la pasión de quién ha escrito la historia: los autores.

Una mención especial, además del excelente trabajo de los autores, corresponde a la Fundación Atlantic Copper que ha editado con extraordinaria calidad una buena investigación que -haciendo mías las palabras de su presidente en el Prólogo- se presenta como una auténtica joya... en cobre y oro, joya en la que han participado otras personas, y que sirve no como ostentación sino como una manera de profundizar en un mejor conocimiento de la metalurgia en el pasado y el presente. Tendiendo hilos de cobre que comunican lo que fue y lo que es. Todo ello hace del libro una experiencia única e innovadora y lo convierte en un hito muy remarcable en la divulgación arqueológica contemporánea.

Gonzalo RuIZ ZAPATERO

Departamento de Prehistoria Universidad Complutense de Madrid gonzalor@ghis.ucm.es

\section{REFERENCIAS BibLIOGRÁFICAS}

Berardinelli, A. (2016): Leer es un riesgo. Círculo de Tiza, Madrid.

CARTER, B. (2014): Boom, Bust, Boom. A story about copper, the metal that runs the world. Schaffner Press.

Connah, G. (2010): Writing about Archaeology. C.U.P., Cambridge.

Roberts, B.W.; Thornton, Ch.P.; Piggott, V. (2009): Development of metallurgy in Eurasia, Antiquity, 83: 1012-1022.

Ruiz Zapatero, G. (2014): Escribir como arqueología. Arqueología como escritura, Anales de Prehistoria y Arqueología, 30: 11-28.

Solana, G. (2013): Comienza \# Thyssen140, mi guía esencial del @museothyssen. A partir de aquí, los tuits van numerados. Leedlos con cuidado, cada palabra cuenta. Museo Thyssen-Bornemisza, Madrid.

Wood, J. (2016): Los mecanismos de la ficción. Taurus, Madrid. 